\title{
FINITE ELEMENT ANALYSIS OF TIMBER BEAMS WITH FLAWS
}

\author{
Janka Kováčiková ${ }^{1,2}$, Mats Ekevad ${ }^{1}$, Ol'ga Ivánková $^{2}$, and Sven Berg ${ }^{1}$ \\ ${ }^{1}$ Luleå University of Technology \\ Division of Wood Science and Engineering, SE-931 87 Skellefteå, Sweden \\ e-mail: janka.kovacikova@stuba.sk,\{mats.ekevad,sven.berg\}@1tu.se \\ ${ }^{2}$ Slovak University of Technology in Bratislava \\ Department of Structural Mechanics, Radlinskeho 11, SK-810 05 Bratislava, Slovakia \\ olga.ivankova@stuba.sk
}

Keywords: FEA, Fracture Mechanics, Timber Beams, XFEM, Wood.

\begin{abstract}
The work was focused on modelling of cracks and simulations of their propagation in timber beams. The aim was to find out the influence of flaws on load-carrying capacity. In beam design and beam inspection, it is necessary to determine the load-carrying capacity of a beam with flaws. There is not much information in literature about the influence of flaws on bending and shear strength of timber beams. Standards for fracture mechanics design approach for timber structures are not easily available.

The results from simulations of loaded timber beams with flaws are discussed in this paper. Two different types of timber beams were analysed. First type was a sawn timber beam and for that four different models were analysed: first model was a beam without flaw; second model was a beam with a straight central flaw; next was a beam with an oblique crack and fourth beam had a round hole in the middle of the span. Second type of beam was a glued laminated timber beam (glulam). For this type, five different models were analysed. First four variants were the same as for the solid timber beam and the fifth variant had an initial crack along a glue line. We analysed these types of flaws, since they are the most common flaws in wood.

Simulations were conducted in ABAQUS. Material properties of wood used in the models were retrieved from standards; C24 for solid timber and GL24c for glulam timber beams. Dimensions of beams were the same for all variants and beams were considered simply supported. For an analysis of crack propagation, linear elastic fracture mechanics was considered. Modelling fracture was conducted using the extended finite element method (XFEM). The energy approach was used for the analysis of crack propagation. Comparing results for solid and glulam beams with and without cracks gave us an overview how different flaws influence load-carrying capacity of the beams and under which loading failure occurs. Simulating timber beams is more complicated compering to steel or plastic. By understanding how to simulate flaws in wood material it is possible to obtain reliable results with finite element analysis.
\end{abstract}




\section{INTRODUCTION}

Sawn timber and glued laminated beams (glulam) are used as bearing structure members of building constructions. Flaws which occur in beams due to different causes can have an effect on their load-carrying capacity. These imperfections can, in the worst case scenario, cause an ultimate failure of the constructions.

This study is focused on simulating different types of flaws in beams and analysing their effect on fracture behaviour and load- carrying capacity of beams. Energy criterion approach was assumed for fracture analysis. This approach states that a crack will grow when the energy required for the crack growth overcome the resistence of the material. $G$ is the energy release rate and the critical value of $G$ is the resistence of the material $G_{c}$. A crack occures at the moment when $G=G_{c}$ and will grow when $G>G_{c}$. This fracture parameter describes fracture behaviour of solids taking into account stress-strain state, and deflections in the area near the crack [1].

Fracture toughness is the ability to withstand flaws that initiate failure. This parameter can be defined for three ways of loading a crack (mode I, II, and III) (Fig.1). The crack or failure occurs when crack is loaded in one of these modes or by their combination.

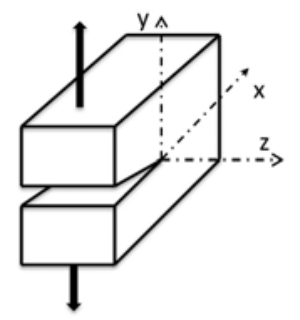

(a)

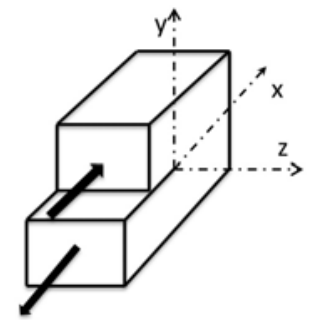

(b)

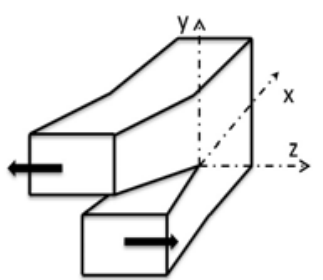

(c)

Figure 1: Modes of loading of a crack: (a) mode I, (b) mode II, (c) mode III

In an orthotropic material such as wood we need to consider not only the mode of loading but also in which plane the crack lies and in which direction it may propagate [2]. A crack can lie in six planes and propagate in one or two direction. Considering 6 planes and 3 modes of loading, 18 basic fracture situations can be identified (Fig.2) [3].
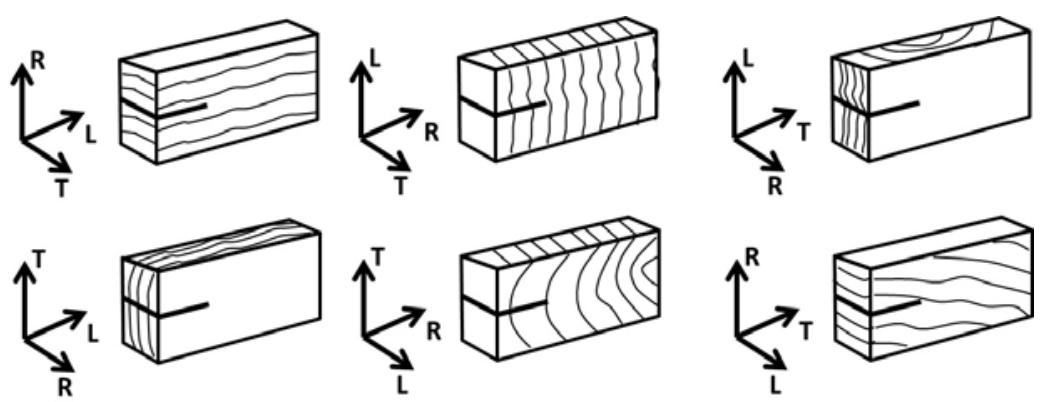

Figure 2: Possible crack propagation situation in wood

Fracture toughness is determined from values of stress intensity factors (SIFs) in modes I, II, III. Stress intensity factors have usually a subscript to denote the mode of loading i.e., $K_{I}$, $K_{I I}$ and $K_{I I I}$. Some closed form solutions for stress intensity factors can be found in fracture mechanics handbooks. These solutions differs for case of loading, stress fields ahead of a crack tip, mode of loading, shape of a crack,... There is a relationship between fracture 
toughness and critical values of energy release rates. When we consider this relationship, we obtain three different values which again depend on the mode of loading; i.e. $G_{I}, G_{I I}$; $G_{I I I}$.

Simulating wood fracture behaviour is a challenging task. Especially, when we consider orthotropic wood models (sawn beams) or transverse isotropic wood models (glulam). Simulations are always three-dimensional (3D). However, investigating fracture behaviour of wood can help us to understand how wood will behave in certain circumstances and how flaws influence its characteristics.

This study is focused on modelling and simulating beams with flaws which can occur on timber beams in practical applications. The effect of the flaws on shear and bending capacity of the timber beams is studied.

\section{MATERIAL AND METHODS}

For this study, two types of beams: sawn timber, labelled N, and glued laminated beams, LN, and five different flaws models were considered. First four models were same for N beams and LN beams. Fifth model was created only for LN beam. First model was beam with no crack (Fig.3 (a)); second model had a central vertical crack (Fig.3 (b)); third beam had an incline crack (Fig.3 (c)); fourth variant was a model with a circular hole (Fig.3 (d)); and last model was a beam with an initial horizontal crack (Fig.3 (e)).

Simulations have been conducted in ABAQUS 6.14-4. Material for sawn timber beam was considered orthotropic linear elastic, which means we used 9 independent elastic constants for describing material response. Material property for glulam beams was considered transverse isotropic. Therefore, 4 independent constants were taken into account. Constants used for material modelling are shown in (Tab.1).

Global coordinate system LRT was used where $\mathrm{L}=1=\mathrm{X}, \mathrm{R}=2=\mathrm{Y}, \mathrm{T}=3=\mathrm{Z}$ and also local coordinate systems were assigned for lamellas in glulam beams describing material orientation. In our simulations, we considered the crack in TR plane and loaded by mode I for first four models. For fifth model, the crack was in RL plane and was loaded by a mixed mode (mode I + mode II).

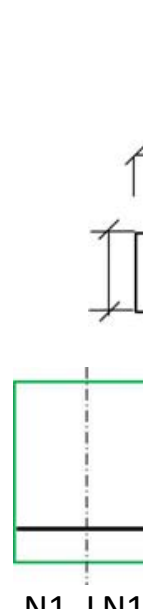

(a)

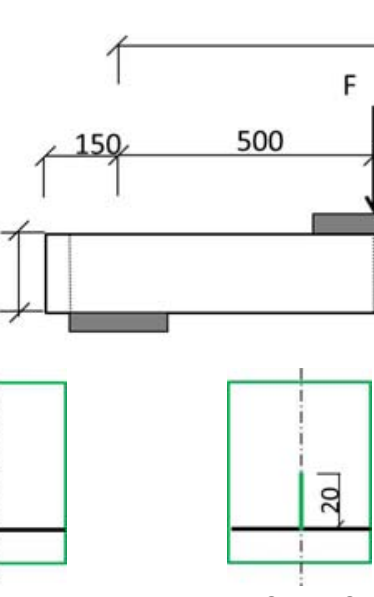

N2, LN2

(b)

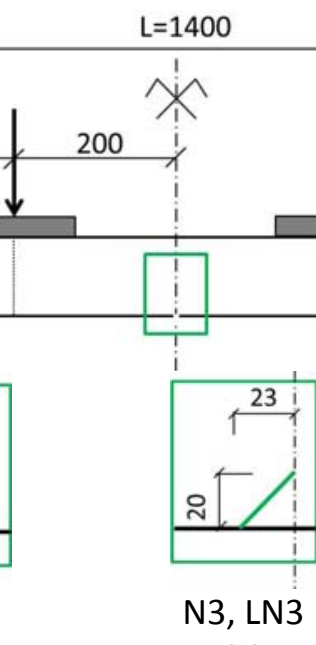

(c)
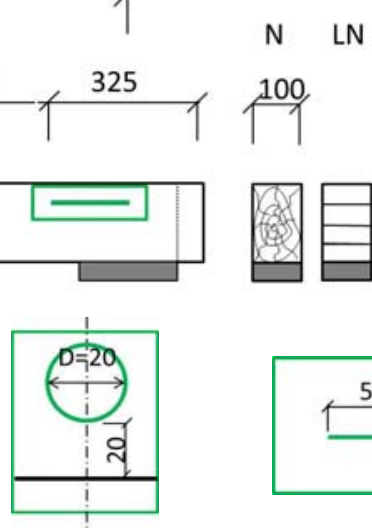

N4, LN4

(d)

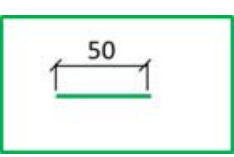

LN5

(e)

Figure 3: Variants of beams

Loading control was used for loading of N1, LN1 beams and deflection control for other types of beams. Therefore, N1 and LN1 beams were loaded by two equally concentrated forces (Fig. 3). Values of loading forces were the ultimate maximum bending and shear forces. Loading forces were: bending force was $20.48 \mathrm{kN}$ for N1 and LN1 (characteristic value of 
maximum bending force), shear force $49.23 \mathrm{kN}$ and $44.8 \mathrm{kN}$ for $\mathrm{N} 1$ and $\mathrm{LN} 1$, respectively (design value of maximum shear force). Forces were analytically obtained considering maximal bending moment; bending strength and maximal shear force; shear strength of a timber simply supported beam with a rectangular cross section loaded by two equal concentrated forces. Beams N2 - N4 have been loaded by $13.32 \mathrm{~mm}$ and LN2 - LN5 by $14.9 \mathrm{~mm}$ which are deflections obtained from a conditional finite element analysis of $\mathrm{N} 1$ and LN1.

Resulting ultimate forces were obtained by analysing dissipation energy and loaddeflections diagrams. Ultimate force was force where a considerable jump in dissipation energy comes into view. This is the force under which beams fail. Also we observed the crack initiation force. It is the force for which a crack starts to propagate; however, jump in dissipation energy is not so significant. In some cases ultimate force is equal to crack initiation force.

\begin{tabular}{|c|c|c|c|c|c|c|c|c|c|c|c|}
\hline \multirow{3}{*}{\multicolumn{2}{|c|}{ Label }} & \multirow{3}{*}{ 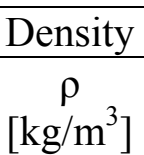 } & \multirow{2}{*}{\multicolumn{3}{|c|}{$\begin{array}{c}\text { Modulus of Elasticity } \\
{[\mathrm{MPa}]}\end{array}$}} & \multirow{2}{*}{\multicolumn{3}{|c|}{$\begin{array}{c}\text { Poisson's ratio } \\
{[-]}\end{array}$}} & \multirow{2}{*}{\multicolumn{3}{|c|}{$\begin{array}{c}\text { Shear modulus } \\
{[\mathrm{MPa}]}\end{array}$}} \\
\hline & & & & & & & & & & & \\
\hline & & & $\mathrm{E}_{\mathrm{LL}}$ & $E_{R R}$ & $\mathrm{E}_{\mathrm{TT}}$ & $v_{\mathrm{LR}}$ & $v_{\mathrm{LT}}$ & $v_{\mathrm{RT}}$ & $\mathrm{G}_{\mathrm{LR}}$ & $\mathrm{G}_{\mathrm{LT}}$ & $\mathrm{G}_{\mathrm{RT}}$ \\
\hline $\mathrm{N}$ & $\mathrm{C} 24$ & 350 & 10700 & 710 & 430 & 0,38 & 0,51 & 0,31 & 500 & 620 & 23 \\
\hline LN & GL24c & 385 & 11000 & 300 & 300 & $0 *$ & $0^{*}$ & $0^{*}$ & 650 & 650 & 23 \\
\hline
\end{tabular}

Table 1: Engineering constants

The XFEM-based LEFM [5] approach was used for simulating crack propagation along an arbitrary, solution-dependent path. Two crack initial criterions were used: the maximum principal stress criterion (MAXPS), and the maximum nominal stress criterion (MAXS). The values for criterions were obtained analytically by considering fundamental laws of elasticity of materials. These criterions were user defined. Value of MAXSP criterion was 24MPa. For defining MAXS criterion it was necessary to define normal-only, first direction and second direction mode. Therefore, for normal-only and first direction mode $24 \mathrm{MPa}$ load was assumed for both types of beams (N, LN). For second direction mode, the criterion was 4.6MPa and 4.2 $\mathrm{MPa}$ for $\mathrm{N}$ and $\mathrm{LN}$ beams respectively.

The virtual crack closure technique (VCCT) fracture criterion was defined. For computing the equivalent fracture energy release rate, the Benzeggagh and Kenane (BK) law was used. The BK law model was described by $[6,7,8]$. Critical values of the energy release which were needed for describing the fracture criterion were: $\mathrm{G}_{\mathrm{IC}}=176 \mathrm{~N} / \mathrm{m}, \mathrm{G}_{\mathrm{IIC}}=734 \mathrm{~N} / \mathrm{m}$ [9]. Value of $\mathrm{G}_{\text {IIIC }}=10000 \mathrm{~N} / \mathrm{m}$ was considered in order to avoid mode III loading for a crack. C3D8 element type for enrichment areas and C3D8R element type for other parts were used in simulations. Enrichment areas were placed where the crack should occur and propagate. In these areas it was needed to consider enrichment functions for the purpose of fracture analysis [5]. Problem size is shown in Tab.3. Interaction between a glue line and lamella was created using surface to surface hard contact.

\begin{tabular}{|l|l|l|l|l|l|l|l|l|l|}
\hline Number & N1 & LN1 & N2 & LN2 & N3 & LN3 & N4 & LN4 & LN5 \\
\hline Elements & 51676 & 63224 & 60692 & 51746 & 117260 & 51746 & 60884 & 54496 & 52768 \\
\hline Variables & 265314 & 372087 & 142188 & 247021 & 428196 & 197988 & 316158 & 178665 & 271398 \\
\hline
\end{tabular}




\section{RESULTS}

The values of maximum forces together with the values of crack initiation forces for all beams are shown in Tab. 4. These values were obtained by analysing damage dissipation energy and load-deflection curves. The load-deflection diagram for all beams is shown in Fig. 4. In these diagrams is shown relationship between deflections vs. maximal load. Deflection was $7.83 \mathrm{~mm}$ for $\mathrm{N} 1,8.13 \mathrm{~mm}$ for $\mathrm{LN} 1,5.18 \mathrm{~mm}$ for $\mathrm{N} 2,7.28 \mathrm{~mm}$ for $\mathrm{LN} 2,3.9 \mathrm{~mm}$ for $\mathrm{N} 3,9.85 \mathrm{~mm}$ for LN3, 4.42mm for N4, 6.99mm for LN4, and $15.86 \mathrm{~mm}$ for LN5.

For $\mathrm{N}$ type beams we obtained following results: $\mathrm{N} 1$ (referential) beam failed under $21.35 \mathrm{kN}$ force. Comparing to the referential flaw-free beam, N1, the load-carrying capacity decreased about $54 \%$ for $\mathrm{N} 2,39 \%$ for N3 and $23 \%$ for $\mathrm{N} 4$.

\begin{tabular}{|c|c|c|c|c|c|c|c|c|c|}
\hline \multirow{2}{*}{ Force $[\mathrm{kN}]$} & \multicolumn{9}{|c|}{ Beam } \\
\cline { 2 - 11 } & N1 & LN1 & N2 & LN2 & N3 & LN3 & N4 & LN4 & LN5 \\
\hline Max. force & $\mathbf{2 1 . 3 5}$ & $\mathbf{2 3 . 2 1}$ & 9.73 & 10.66 & 13.02 & 21.37 & 16.41 & 19.40 & 45.55 \\
\hline Initial crack force & $\mathbf{2 1 . 0 8}$ & $\mathbf{2 3 . 2 1}$ & 7.89 & 8.07 & 13.02 & 10.33 & 16.41 & 12.59 & no \\
\hline
\end{tabular}

Table 4: Resulting values for beams obtained by XFEM analysis

LN1 beam failed under $23.21 \mathrm{kN}$ loading force. Load-carrying capacity decreased about $54 \%, 8 \%$, and $16 \%$ for LN2, LN3, LN4 beams respectively. Different results were obtained for LN1 and LN5 beams. In this case, the load - carrying capacity increased about $96 \%$.

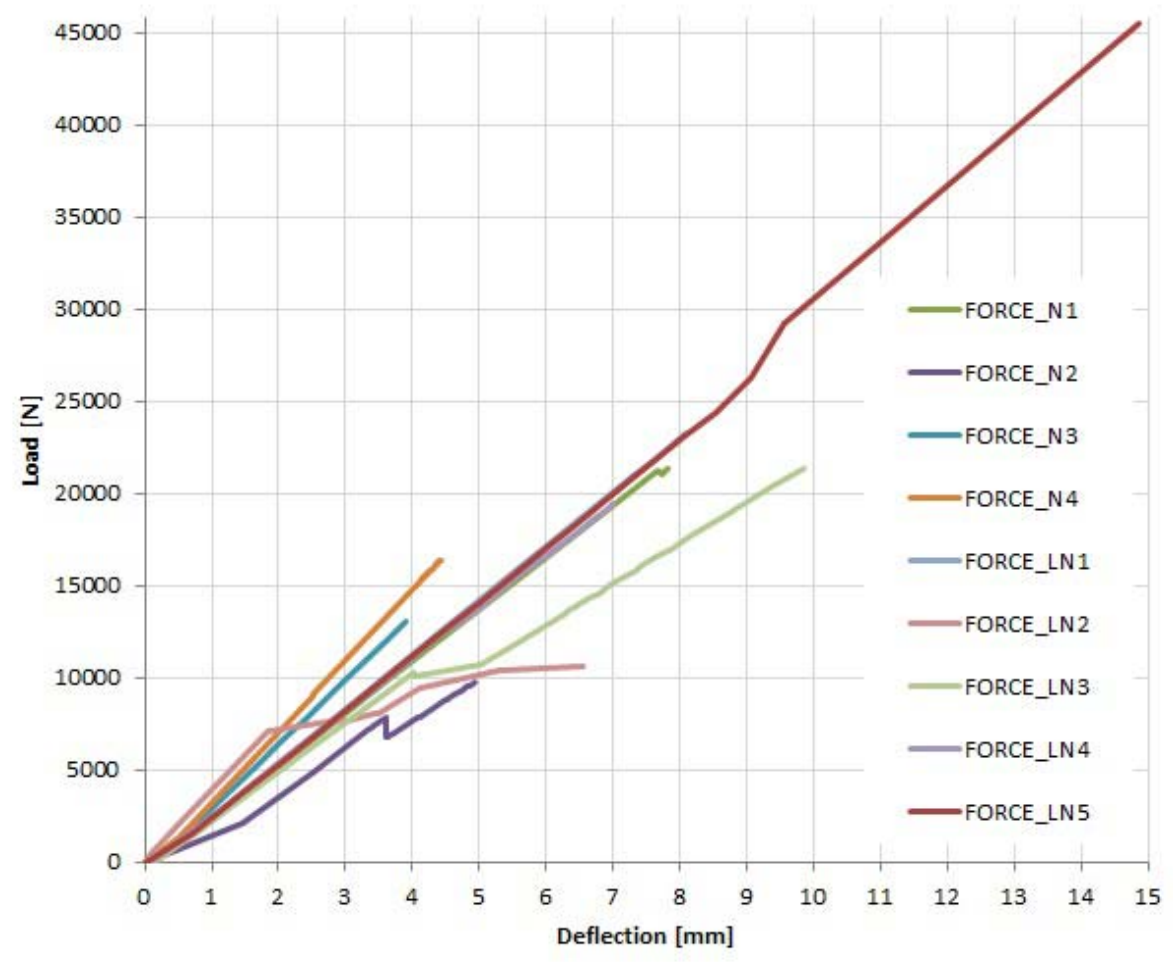

Figure 4: Load-deflection diagrams

\section{DISSCUSION}

Analysing results we can state that the worst influence on load-carrying capacity within the studied models has a vertical initial crack in the middle of a beam's span, for N2 and LN2 
beams. In this case, beams will fail under much lower force compared to the flaw-free beam. $\mathrm{N} 2$ and LN2 beams can carry only $46 \%$ of the referential load. Load - carrying capacity decreased significantly also for the N3 type beam. This beam could carry only $61 \%$ of the reference beam loading. For the LN3 beams decreasing of load-carrying capacity is not so significant. Glulam beam with the oblique crack can carry $92 \%$ of the referential loading. Significant influence on load-carrying capacity had the circular hole in the middle of the beam's span. The N4 and LN4 beams can withstand $77 \%$ and $84 \%$ of the referential force, respectively. Interesting increase in load-carrying capacity was observed for the LN5 beam. In this case capacity of beam increased about $96 \%$ for $14.9 \mathrm{~mm}$ deflection. No jump in dissipation energy occurred in this case. This significant increase of capacity might be caused by stress concentration near this crack and the position of the initial crack. However, it might be also due to numerical errors in FEA analysis. It is needed to study more models and to look at the influence of user-defined parameters. In order to understand why this significant increase of load-carrying capacity occurred, it is necessary to compare the simulation results with experimental ones.

Generally, we can say that flaws have negative influence on load-carrying capacity of beams. Influence of flaws on load-carrying capacity is worse on sawn beams than on glulam beams. It validates our hypothesis that glulam beams are able to bear a higher loading. Positive effect on load-carrying capacity of beams had the horizontal crack on glulam beam. Future work will be focused on studying the effect of this crack type on load-carrying capacity.

\section{REFERENCES}

[1] T.L. Anderson, Fracture Mechanics - Fundamentals and Applications, Third edition. Boca Raton : CRC Pres. Taylor \& Francis Group, 2005. p. 611. 13: 978-1-4200-5821-5.

[2] Laboratory, Forest Products. Wood Handbook. Wood as an Engineering Material. Madison : United States Department of Agriculture Forest Service, 2010. p. 508.

[3] S. Aicher, P.J. Gustafsson, P. Haller, H. Petersson, Fracture mechanics models for strength anylysis of timber beams with hole ore notch. A Report of RILEM TC-133, Lund : Structural Mechanics, LTH, Sweden, 2002. ISSN 0281-6679

[4] EN 1995-1-1:2004, Euro code 5

[5] 6.14-4, Abaqus/CAE Users guide.

[6] D. Xie., S.B. Biggers Jr, Progressive crack growth analysis using interface element based on the virtual crack closure technique. 11, 2006, Finite Elements in Analysis and Design, Zv. 42, p. 977-984. 0168-874X.

[7] G.E. Mabson, L.R. Deobald, B. Dopker, D.M. Hoyt, J.S. Baylor, D.L. Graesser, Fracture interface elements for static and fatigue analysis.. [ed.] 16th International conference on composite materials. Kyoto : s.n., 2007.

[8] A. Leski, Implementation of the virtual crack closure technique in engineering FE calculations. 3, 2007, Finite Elements in Analysis and Design, Zv. 43, p. 261-268. 0168$874 X$.

[9] P. Haller, R. Putzger, Fracture Energy in Mode I and Mode II of Reinforced Wood. Dresden : Technische Universität Dresden: Eigenverlag, 2003. Proceedings of the 2nd Colloquium on Textile Reinforced Structures CTRS2. s. 247-258. 